\title{
Democracia e Ética profissional: a aproximação do debate da democracia e a esquerda brasileira nos anos de 1980 e 1990
}

\author{
Democracy and Professional Ethics: the approach of the democracy debate \\ and the Brazilian left in the years 1980 and 1990
}

\section{Resumo:}

Fatima Grave Ortiz * O artigo propõe resgatar o debate sobre o tema da democracia como caminho possível para o socialismo realizado por intelectuais da esquerda brasileira nos anos de 1980 e 1990, apontando a importância deste polêmico debate para a designação da democracia como princípio ético-político do atual código de ética profissional.

Palavras-chave: Democracia. Socialismo. Ética profissional.

\begin{abstract}
The paper intends to rescue the debate made by intellectuals of Brazilian left wing about democracy as a possible pathway to the socialism during 1980 s and 1990s, showing the importance of this controversial debate to the democracy and its application as ethical and political principle to current professional ethics code.
\end{abstract}

Keywords: Democracy. Socialism. Professional ethics.

\section{Introdução}

O presente artigo é produto da pesquisa intitulada "Democracia e Serviço Social: uma análise sobre as implicações das concepções marxistas e marxiana de democracia para a profissão nos anos 1990 e desdobramentos contemporâneos" (ORTIZ, 2015) e constituiu-se a partir da inter-relação de alguns fatores. O primeiro deles consiste na própria trajetória profissional e acadêmica como pesquisadora, sobre a qual se destaca a prevalência do desenvolvimento de pesquisas voltadas para o Serviço Social, tanto na esfera da formação quanto do exercício profissional.

Outro aspecto relacionado a este diz respeito à vinculação como pesquisadora da Área de Serviço Social em Núcleo de Pesquisa sobre os fundamentos do Serviço Social, sempre desenvolvendo pesquisas bibliográficas e empíricas e nos últimos semestres integrando as discussões do referido núcleo de pesquisa, cujos debates tem se centrado

\footnotetext{
* Doutora em Serviço Social pela UFRJ, professora de Serviço Social na UFRJ. E-mail: fgraveortiz@gmail.com
} 
sobre a temática da concepção marxista e marxiana do direito e suas implicações ao Serviço Social.

Por fim, outro elemento que consideramos de grande relevância diz respeito à vivência como professora da disciplina de Ética Profissional no período de 2007 a 2016 em curso de graduação de Serviço Social e anos depois - já a partir de 2010 - no Programa de Pós-Graduação em Serviço Social da mesma unidade de formação acadêmica, ministrando disciplinas vinculadas aos fundamentos do Serviço Social e da ética.

No entanto, a experiência como docente - tanto em nível da graduação quanto de pós-graduação - tem nos alertado quanto a dois aspectos autoimplicados que dizem respeito diretamente ao ensino da ética profissional: a complexidade dos seus conteúdos e a necessidade de capacitação permanente do docente para o encaminhamento da disciplina somado às dificuldades de apreensão por parte dos discentes, por um lado; e por outro a inexorável necessidade de transversalidade da ética na formação profissional como exigência central para a formação de novas gerações de profissionais conforme o perfil previsto nas Diretrizes Curriculares.

A reflexão e o ensino da ética e da ética profissional exigem que os pesquisadores da área estejam sempre atentos aos seus fundamentos e sua vitalidade histórica e conceitual, o que não significa subestimar as contradições presentes em todo o processo que culminou nos idos de 1990 com a aprovação do código de ética profissional atual.

Neste sentido, a análise crítica dos fundamentos do Serviço Social e da ética nos permite entender que, se por um lado, o Código de Ética dos Assistentes Sociais revela determinada direção social e política ao dever ser profissional e ao exercício da profissão em si condizente com o projeto profissional hegemônico; por outro, é absolutamente necessário que tenhamos clareza do alcance e da posição ético-política expressa em cada um de seus princípios.

Dentre os princípios, identificamos a defesa da democracia como um dentre os demais a serem seguidos pelos assistentes sociais. E é sobre a democracia que este texto se propõe a tratar, mais especificamente pretende resgatar seu debate existente no campo da esquerda brasileira nas décadas de 1970 e 1980. Entendemos que a apreensão crítica da concepção de democracia se faz importante para melhor 
entendermos de que modo e porque esta se expressa em nosso atual código de ética profissional e que polêmicas tal fato revela.

\section{Objetivos}

Constitui-se como objetivo central deste artigo apresentar, nos limites deste, o debate da democracia no âmbito da esquerda brasileira nos anos de 1970 e 1980. Serão apresentadas também as novas perspectivas postas para nossa pesquisa, visto que o ponto de chegada de um processo investigativo encerra o ponto de partida de novas pesquisas.

\section{Justificativa}

O artigo justifica sua relevância a partir de pelo menos dois conjuntos de problemas: um de caráter mais amplo que diz respeito a formação social brasileira e outro que incide diretamente sobre as conquistas do Serviço Social brasileiro nos anos 80 e 90 do século XX, no tocante a adesão da categoria profissional (ou de pelo menos parte dela) e suas entidades a determinados valores emancipatórios e seu correspondente projeto societário anticapitalista.

Quanto ao primeiro, sua importância reside no fato de que ao longo de quinhentos anos de história, poucos foram os momentos em que o Brasil viveu sob a regência da democracia. Ademais, podemos afirmar que sem contarmos as fases colonial e imperial, o Brasil viveu, pelo menos em três momentos de sua recente história, processos ditatoriais: em 1889 com a proclamação da República e a instauração dos governos provisórios e constitucional presididos respectivamente por Deodoro da Fonseca e Floriano Peixoto; em 1937 com o Estado Novo de Vargas e em 1964 quando se instaurou a ditadura civil-militar, da qual o Brasil apenas teve condições de superar nos anos 1980. Tais processos somam-se ao recente impeachment da presidente Dilma Rousseff e a instauração de um "golpe institucional", mascarando manobras que as elites brasileiras historicamente empreendem quando precisam garantir seus interesses políticos e econômicos. Estes aspectos podem nos elucidar em primeira instância porque o apelo à democracia nos é tão frequente e importante.

Contudo, uma análise um pouco mais apurada, demonstra que o tema da democracia tomou parte dos debates no campo da tradição marxista na esteira da crise 
do chamado socialismo real e do avanço do "eurocomunismo", animando os debates e a polêmica no campo da esquerda em torno da tese do caráter universal da democracia e da sua defesa como saída para a construção do socialismo. A referida tese incidiu fortemente nos círculos da esquerda brasileira, alcançando no final dos anos de 1970 e 1980 quadros importantes do então jovem Partido dos Trabalhadores, que contou historicamente em suas fileiras com assistentes sociais.

A partir deste debate, a defesa da democracia foi incorporada por pelo menos uma vanguarda dos assistentes sociais brasileiros ainda nos anos de 1980 . Nos anos de 1990, a democracia passa de modo contundente, a expressar-se como um princípio ético-político ao lado de outros dez no Código de Ética em vigor: "Defesa do aprofundamento da democracia, enquanto socialização da participação política e da riqueza socialmente produzida" (CFESS, 1993).

Deste modo, com este princípio, espera-se que os assistentes sociais atuem de forma a garantir o acesso dos usuários aos processos e decisões institucionais, rompendo com a tutela e o assistencialismo. Contudo, além da vinculação com a participação política, o referido princípio relaciona a necessidade de aprofundamento da democracia como medida para a socialização da riqueza produzida. Neste sentido, qual concepção de democracia está aqui subjacente? Em que medida por meio da democracia poderá a classe trabalhadora ter acesso à riqueza socialmente produzida?

Assim, este artigo traz a público o esforço de reflexão que tem sido realizado no projeto de pesquisa supracitado sobre o tema da democracia, partindo do debate realizado nos anos de 1980 na esquerda brasileira acerca da questão.

\section{Método}

Como afirmado ainda na introdução deste artigo, este é produto de um processo de pesquisa, que apoiado no método crítico-dialético caracterizado por Marx (1974), pressupõe a autoimplicação entre sujeito e objeto, embora este último exista independente do conhecimento do sujeito que investiga ${ }^{1}$. Já o sujeito, portador de valores e interesses, enfim de um determinado padrão de sociabilidade, nunca é neutro.

\footnotetext{
1 Tal entendimento repousa na perspectiva de que o processo de gênese do real é diferente daquele que consiste na apreensão do objeto pelo intelecto. Enquanto o primeiro parte dos elementos simples que se complexificam; o segundo faz o caminho exatamente inverso.
} 
Nesta relação estabelecida entre o objeto pesquisado e o sujeito que pesquisa não há prioridade entre um e outro, tal como a pesquisa de cunho positivista, na qual o objeto é o prevalente; mas uma interconexão, pois ambos participam de uma mesma totalidade, compondo o ser social.

Assim, ainda que sujeito e objeto componham a mesma totalidade - entendida enquanto "unidade do diverso", este último não se encontra naturalmente desvelado; e além disso, a realidade é sempre muito mais rica do que pode supor nosso intelecto, é por isso que "o conhecimento dialético tem em Marx o caráter de mera aproximação" (LUKÁCS, 1979, p. 108).

No entanto, a despeito da riqueza do mundo real e do caráter do objeto, nos é possível conhecer efetivamente determinado fenômeno por meio das aproximações sucessivas, uma vez que nos "é perfeitamente possível descobrir as leis mais gerais do movimento da economia e, com seu auxílio, conhecer a linha de fundo do desenvolvimento histórico, não só como é de fato, mas também elevado a conceito." (LUKÁCS, 1979, p.109). Ou seja, através do método dialético marxista podemos, não somente identificar as determinações do objeto, mas apreendê-lo pela via do pensamento como concreto pensado, com a finalidade de sobre ele intervir.

Assim, exatamente porque o objeto não está dado, o método dialético "parte da preliminar de que a realidade social não se dá a conhecer, a não ser pela reflexão demorada, reiterada e obstinada" (IANNI, 1986, p. 3). A não conformação com a aparência dos fenômenos deve se constituir enquanto a base da crítica que a pesquisa deve empreender.

Com efeito, considera-se que o objeto de uma pesquisa social, sobretudo como a nossa, deve exigir uma análise essencialmente qualitativa, na qual a reflexão teórica e histórica sobre ele deve ser imprescindível. Este artigo, portanto, apresenta, apesar dos limites que Ihes são colocados, por meio de pesquisa bibliográfica, as considerações sobre a temática da democracia feitas pela tradição marxista no Brasil nos anos de 1970 e 1980.

\section{Resultados obtidos}

A pesquisa bibliográfica realizada demonstrou que ainda nos anos de 1960 o debate da relação entre democracia e política foi retomado a partir dos acontecimentos 
histórico-políticos que se constituíram com o stalinismo e com os rumos tomados pela então União Soviética. Conforme Buonicore (2006, p. 3),

[...] O debate sobre a relação entre democracia e socialismo voltou à tona na década de 1960. Mas foi, sem dúvida, com o surgimento da corrente eurocomunista que ele passou a ter um lugar central na agenda teóricopolítica das organizações da esquerda mundial. Entre os principais expoentes desta nova corrente estavam Marchais, Berlinguer e Santiago Carrilho, respectivamente secretários-gerais dos Partidos Comunistas da França, Itália e Espanha.

Em linhas gerais, para tal corrente a democracia expressaria a forma superior de liberdade humana, e apenas poderia se desenvolver plenamente quando em uma sociedade socialista, estivesse completamente livre das desigualdades impostas pela ordem burguesa. Extinta a sociedade de classes, a democracia poderia alçar sua condição de propiciadora de um novo grau da existência humana. A democracia, portanto, poderia ser vista como um caminho importante a ser trilhado para o triunfo do próprio socialismo (ORTIZ, 2015).

Moraes (2001, p. 22), neste sentido, adverte que,

[...] o reconhecimento do nexo entre democracia e socialismo não é monopólio de nenhuma corrente de esquerda. A tese de que o socialismo resultaria do aprofundamento e da ampliação das instituições democráticas forjadas no capitalismo não constituía novidade. Ao contrário, havia sido sustentada pela II Internacional, cujos partidos-membros se intitulavam social-democratas exatamente para marcar o vínculo que declaravam essencial entre democracia e socialismo. Toda a dificuldade, evidentemente, consistia (e continua consistindo) em determinar a natureza deste nexo, ou, mais dinamicamente, a lógica objetiva deste processo.

No Brasil, este debate chegou nos anos de 1970 na esteira do discurso de Berlinguer, dirigente socialista italiano, que em 1977 durante as comemorações dos 60 anos da Revolução Russa afirmou que "a democracia é hoje não apenas o terreno no qual o adversário de classe é obrigado a retroceder, mas é também o valor historicamente universal sobre o qual fundar uma original sociedade socialista" (apud MORAES, 2001, p.9).

Toledo (1994, p. 28) pondera, entretanto, que as experiências do socialismo real e das ditaduras civis-militares no Brasil e em outros países da América Latina 
fortaleceram na pauta da esquerda brasileira o tema da democracia. "Para significativos setores da esquerda, a defesa da democracia não deve ser mais um valor tático, mas adquirir um valor estratégico, um valor em si mesmo."

Nesta direção, credita-se aos ensaios de Coutinho (1979) - A democracia como valor universal e de Weffort (1984) - Por que Democracia? As principais contribuições da esquerda brasileira para o espraiamento da defesa da democracia como meio inexorável para a construção do socialismo. Era preciso se reabilitar a democracia, colocando-a no centro da transição para o socialismo, tendo em vista que estando a serviço dos interesses dos trabalhadores, universaliza-se, pois passa compor o rol das conquistas humano-genéricas. A democracia, para Weffort (1984) neste sentido, não seria um instrumento fundamentalmente burguês, mas objeto de disputa entre as classes (ORTIZ, 2015).

Os críticos da tese da "universalidade da democracia" (TOLEDO, 1994; MORAES, 2001, 1999; TONET, 2011, dentre outros) afirmavam que no âmago desta está a crença na possibilidade de construção de uma nova ordem societária por dentro das instituições democráticas burguesas, disputando sua hegemonia, construindo, assim, o projeto de "democracia de massas" (COUTINHO, 2000). Caberia aos trabalhadores, lutar pelo alargamento da democracia política, disputando a direção política, ideológica e cultural do Estado e suas instituições. Subjaz a este entendimento, a apreensão da concepção gramsciana de Estado Ampliado (sobretudo, no caso de Coutinho - seu conhecido e competente intérprete), na qual o Estado por não ser mais o instrumento exclusivo da classe dominante, vê-se obrigado a ampliar suas bases de legitimidade junto ao conjunto da sociedade civil, incluindo, desta maneira, as reivindicações dos trabalhadores. A disputa pelas bases desta ampliação consiste, conforme os autores supracitados, estratégia central para a constituição do "caminho democrático para o socialismo" (TONET, 2011).

Para os autores que criticam a tese da universalização de democracia, é certo que o Estado está a todo tempo atravessado por contradições, mas é certo também que ele não é neutro, mas possui um conteúdo de classe. Disputar espaço dentro deste Estado é sem dúvida importante, mas "seria ilusório pensar que as classes e frações venham ocupar posições semelhantes ou de equilíbrio em seu interior" (TOLEDO, 1994, p. 34). Ademais, não podemos entender que a existência da democracia é fruto exclusivo das 
lutas da classe trabalhadora. Para Toledo (1994) a democracia e os processos que ela promove, tendem também a interessar e legitimar os interesses burgueses. Ou seja, não é uma via de mão única. Vejamos o que afirma Toledo (1994, p. 35) nesta direção:

\begin{abstract}
Como é sempre relevante ressaltar, a supressão da democracia política é particularmente desastrosa para as classes trabalhadoras e populares. Mas, essa mesma democracia - necessariamente classista nos quadros da ordem capitalista, ao contrário do que julga a esquerda "moderna" - tem sido também um poderoso instrumento para a garantia e reprodução da ordem desigual, na medida em que seus efeitos ideológicos têm contribuído para privar a classe trabalhadora da possibilidade de conceber um outro tipo de Estado e sociedade. Se os regimes democráticos permitem efetivas conquistas sociais e políticas para as massas populares, a sua idealização tem tido um efeito mistificador e contrarrevolucionário.
\end{abstract}

É inegável que a existência de conjunturas democráticas tende a facilitar a organização da classe, e neste sentido, os vinte anos de ditadura civil-militar trouxeram para o Brasil reveses que são sentidos até hoje tanto do ponto de vista político e cultural, como também econômico. No entanto, tomar a democracia [e seu alargamento institucional] como estratégia para a construção de uma sociedade plenamente emancipada, embora não signifique diretamente a opção por uma saída reformista, também não explicita a exigência da ruptura com a sociedade hegemônica para o florescimento do socialismo, mas a tendência a um aprimoramento da primeira. No dizer de Moraes (2001, p. 20), "para o marxismo, a democracia, como forma de Estado, tão pouco é um fim em si (um 'valor universal'), e sim, um instrumento de dominação política”.

Leitura semelhante é possível se encontrar nos escritos do próprio Marx. Para Marx, a categoria central de toda sua análise para a compreensão do homem e da totalidade social é o trabalho, não o Estado, a política ou a democracia, mas o trabalho. É o trabalho o fundamento ontológico que funda o ser social, que possibilita a construção de sua sociabilidade. Já o Estado, conforme Marx, emerge a partir do surgimento das classes sociais, da propriedade privada e do antagonismo presente entre elas. O Estado surge então como ente presente nesta correlação de forças, não para arbitrar acima delas, mas para defender os interesses daqueles que na sociedade de classes dominam. O Estado possui, portanto, um claro conteúdo de classe em suas ações, orientações políticas e instituições. 
Deste modo, no capitalismo o Estado é, acima de tudo, burguês, apesar deste modo de produção inovar na maneira de operar a relação de exploração de um homem (capitalista) sobre o outro (trabalhador). Na ordem burguesa, tendo em vista que são apresentados ao mercado, ambos são livres proprietários, que juntos firmam um "contrato de trabalho" - contratante e contratado. Ambos se apresentam, desta forma, como iguais. Contudo, trata-se da "igualdade jurídica", tão bem alertada por Marx (2010), e não da igualdade em si - esta impensável e uma abstração em uma sociedade de desiguais. O contrato de trabalho "[...] articula em si dois momentos: o momento da desigualdade real e momento da igualdade formal. " (TONET, 2011, p. 8). Caberá o Estado, por meio da forma jurídica, regular estas relações, conferindo-lhes legalidade e perenidade, assumindo a forma política exigida pelo sistema de trocas específico do capitalismo (MASCARO, 2013).

Assim, como esperar que a democracia seja usada como expediente capaz de demolir o Estado e a sociedade capitalista, possibilitando o acesso à riqueza socialmente produzida?

\section{Considerações finais}

A análise que foi feita até aqui neste artigo tentou se aproximar do entendimento marxiano acerca da democracia e o debate realizado na tradição marxista nas últimas décadas sobre este tema. Há de se reconhecer o papel histórico da democracia na ruptura com o Antigo Regime e as monarquias absolutistas e com tudo que estes representavam. Há de se entender também que o regime democrático tende a favorecer a organização política da classe trabalhadora, tendo em vista que a transição da sociedade capitalista à socialista e, posteriormente, desta à comunista, exigirá a radicalização prévia da participação política (e, portanto, democrática) de todos. No entanto, uma vez alcançada a transição, a via democrática será sempre insuficiente para a construção de uma nova ordem societária. Para Marx, a democracia consiste inequivocamente em uma esfera pertencente a ordem burguesa, que tenderá a desaparecer com ela em uma sociedade constituída por livres produtores associados.

Deste modo, a luta por democracia deverá ser sempre tratada como meio para a construção de uma sociedade sem privilégios, sem preconceitos e discriminação, e 
nunca como meio em si capaz de proporcionar a transição do capitalismo ao socialismo e nem deste ao comunismo.

Cabe ressaltar também que, a partir de resgate da produção de intelectuais da esquerda brasileira dos anos de 1970 e 1980, tem sido bastante polêmica - tanto no interior da tradição marxista quanto na observação dos processos históricos em si - a afirmação de que é possível se construir uma sociedade socialista pela via democrática. Uma breve análise da história recente dos caminhos de determinados setores da esquerda brasileira demonstrou como nos anos de 1980, muitos de seus intelectuais aderiram a tese do "socialismo democrático" ou da identificação do caráter universal da democracia como caminho para a construção do socialismo. Tal perspectiva, inclusive fundamentou o chamado projeto democrático-popular, o qual contou com a adesão de muitos quadros profissionais do Serviço Social.

Assim, entendemos que o resgate e leitura crítica de tais referências tendem a lançar luz sobre a trajetória sócio-histórica e a posição ético-política assumidas pela vanguarda do Serviço Social brasileiro nas últimas décadas do século XX, culminando com a aprovação do código de ética profissional em vigor e neste na defesa de seus princípios dentre eles a democracia.

\section{Referências}

BUONICORE, Augusto. Qual o valor da democracia? 2006. Disponível em: <http://www.fundaj.gov.br/geral/observanordeste/buonicore\%20rev.pdf>. Acesso em: 13 fev. 2016.

CFESS. Conselho Federal de Serviço Social Código de Ética dos Assistentes Sociais. Brasília, 1993.

COUTINHO, Carlos Nelson. A Democracia como valor universal. Rio de Janeiro: Civilização Brasileira, 1979.

COUTINHO, Carlos Nelson. Contra a Corrente: ensaios sobre democracia e socialismo. São Paulo: Cortez editora, 2000.

IANNI, Otavio. A Construção da Categoria. São Paulo: Pontifícia Universidade Católica de São Paulo, 1986. Mimeo.

LUKÁCS, Gyorgy.Ontologia do Ser Social - Os Princípios Ontológicos Fundamentais de Marx. São Paulo: Editora Ciências Humanas, 1979.

MARX, Karl. Sobre a Questão Judaica. São Paulo: Boitempo Editorial, 2010. 
MARX, Karl. Para a Crítica da Economia Política. São Paulo: Abril Cultural, 1974. (Coleção Os Pensadores).

MASCARO, Alysson Leandro. Estado e Forma Política. São Paulo: Boitempo Editorial, 2013.

MORAES, João Quartim de. A Universalidade da Democracia: esperanças e ilusões. Ad Hominen - Revista de Filosofia,Política/Ciência da História, São Paulo, tomo 1, 1999.

MORAES, João Quartim de. Contra a Canonização da Democracia. Crítica Marxista, São Paulo, n. 12, p. 9-40, 2001.

ORTIZ, Fátima Grave. Democracia e Serviço Social: uma análise preliminar sobre as implicações das concepções marxistas e marxianas de democracia para a profissão. Revista Serviço Social, Brasília, v. 17, n. 36, p. 68-83, 2015.

TOLEDO, Caio Navarro de. A Modernidade Democrática da Esquerda: adeus à revolução? Crítica Marxista, São Paulo, v.1, n.1, p. 27-38, 1994.

TONET, Ivo. Marxismo e Democracia, 2011. Disponível em: <www.ivotonet.xpg.uol.com.br>. Acesso em: 28 abr. 2016.

WEFFORT, Francisco C. Por que democracia?. 2. Ed. São Paulo: Brasiliense, 1984. 